\title{
Neuroprotective Effect of Juniperus communis on Chlorpromazine Induced Parkinson Disease in Animal Model
}

\author{
Souravh Bais, ${ }^{1}$ N. S. Gill, ${ }^{2}$ and Nitan Kumar' \\ ${ }^{1}$ Department of Pharmacology, Rayat Institute of Pharmacy, Railmajra, Shaheed Bhagat Singh Nagar, Punjab 144533, India \\ ${ }^{2}$ Department of Pharmaceutical Chemistry, Rayat Institute of Pharmacy, Railmajra, Shaheed Bhagat Singh Nagar, \\ Punjab 144533, India
}

Correspondence should be addressed to Souravh Bais; souravh2008.123@rediffmail.com

Received 28 September 2014; Revised 8 January 2015; Accepted 26 January 2015

Academic Editor: Qiusheng Zheng

Copyright (C) 2015 Souravh Bais et al. This is an open access article distributed under the Creative Commons Attribution License, which permits unrestricted use, distribution, and reproduction in any medium, provided the original work is properly cited.

\begin{abstract}
We evaluated anti-Parkinson's activity of methanolic extract of Juniperus communis (MEJC) leaves in chlorpromazine (CPZ) induced experimental animal model. In this study effects of Juniperus communis (100 and $200 \mathrm{mg} / \mathrm{kg}$, i.p.) were studied using various behavior parameters like catalepsy (bar test), muscle rigidity (rotarod test), and locomotor activity (actophotometer) and its effect on neurochemical parameters (TBARS, GSH, nitrite, and total protein) in rats. The experiment was designed, by giving chlorpromazine $(3 \mathrm{mg} / \mathrm{kg}$, i.p.) for 21 days to induce Parkinson's disease-like symptoms. Chlorpromazine significantly induced motor dysfunctions (catalepsy, muscle rigidity, and hypolocomotion) in a period of 21 days. The MEJC significantly $(P<0.001)$ reduced catalepsy and muscle rigidity and significantly $(P<0.001)$ increased locomotor activity in rats. The maximum reduction was observed on the 21st day at a dose of $200 \mathrm{mg} / \mathrm{kg}$ (i.p.). The MEJC extract also showed an increase in the level of reduced gutathione $(\mathrm{GSH})(P<0.001)$ and total protein $(P<0.001)$ and decreased the elevated levels of TBARS $(P<0.001)$ and nitrite $(P<0.001)$ preferably at a higher dose $(200 \mathrm{mg} / \mathrm{kg})$ as compared to chlorpromazine group. Thus the present study showed the neuroprotective effect of MEJC against CPZ induced Parkinson's disease-like symptoms or anti-Parkinson's activity.
\end{abstract}

\section{Introduction}

Parkinson's disease (PD) is a neurodegenerative brain disorder. It is mainly characterized by progressive loss of dopaminergic and other neurons present in the substantia nigra pars compacta resulting in malfunctioning of the cerebral neuronal systems. Clinically the disease may cause slowness of movement, muscle rigidity, and rest tremor [1]. Pathologically, Parkinson disease may cause depletion of dopamine in brain due to the presence of intracytoplasmic inclusions known as Lewy bodies. It is not clear why Lewy body formation causes neuronal cell death. These pathological changes are also seen in the locus coeruleus and parasympathetic as well as sympathetic postganglionic neurons, pedunculopontine nucleus, raphe nucleus, and dorsal motor nucleus of the vagal nerve [2]. The Parkinson disease can be treated with various drugs including levodopa, carbidopa, orphenadrine, benztropine, selegiline, pergola, and many more which act by reversing the symptoms of Parkinson's disease but these drugs possess various side effects like nausea and vomiting, respiratory disturbances, hallucinations, orange discoloration of saliva and urine, mania, dyskinesia convulsions and anxiety, arrhythmia, mydriasis, dry mouth, sore throat, and transient dizziness on long term use [3].

Oxidative stress also plays a major role in the pathophysiology of PD. Oxidative stress may cause neurodegeneration of neuronal cells. Oxidative stress may cause depletion of enzymes such as catalase, superoxide dismutase, and glutathione [4].

J. communis $\mathrm{L}$. is a shrub belonging to family Cupressaceae L. mainly found in Himachal Pradesh (India) at an altitude of 1500-4000. Fruit is subspherical, purplish-black and seed contained 2-3 layers of thin-walled cells. The seeds and fruits of the plant contain camphene, $d-\alpha$-pinene, formic acid, acetic acid, wax, gum, cyclohexinol, terpene, ascorbic acid, dihydrojunene, cadinene, juniper, and camphor [5-7]. The J. communis (berry) oil mainly contained monoterpene hydrocarbons such as $\alpha$-pinene (51.4\%), $\beta$-pinene (5.0\%), sabinene 
(5.8\%), and myrcene (8.3\%) [8]. J. communis can be used (traditionally) for renal suppression, acute and chronic cystitis, catarrh of the bladder, albuminuria, leucorrhoea, and amenorrhoea [9]. J. communis fruit can be used as being antiseptic, stimulant, and styptic. It can also be used in the treatment of migraine, infantile tuberculosis, rheumatic and painful swellings, chronic Bright's disease, piles, and nephrotic dropsy of children [6]. The plant was reported to have analgesic activity [10], antibacterial activity [11], hepatoprotective activity [12], antihypercholesterolemic activity [13], antiinflammatory activity [14], antidiabetic and antihyperlipidemic activity [15], anticataleptic activity [16], and antimicrobial [17] activity. Previous study indicates that Parkinson's disease occurs due to the increased oxidative stress [18] and several plants with antioxidant activity have been found to be effective in the treatment of disease [8]. Thus the study aimed at screening of the plant for its anti-Parkinson's activity.

\section{Materials and Methods}

2.1. Animals. Experiments were carried out on Wistar rats (150-200 g) of either sex and were obtained from the Lokan Thermometer (Ambala, India). They were housed under standard light/dark cycle and fed with standard pellet diet and water ad libitum. The experimental protocols were approved by the Institutional Animal Ethics Committee and conducted according to the guidelines of Committee for the Purpose of Control and Supervision of Experiments on Animals (CPCSEA), New Delhi, India.

2.2. Procurement of Plant Material. Standardized dry methanolic extract of leaves was obtained from Amsar Pvt. Ltd., Indore (M. P.). The extract dose was prepared using $2 \% \mathrm{CMC}$ (suspending agents) prior to administration.

2.3. Drugs and Chemicals. Chlorpromazine, levodopa, and carbidopa were procured as gift sample from Sun pharmaceuticals (Baddi, India). All chemicals are of analytical grade and are purchased from Spruce Enterprises Ambala Cantt (Punjab, India).

2.4. Phytochemical Evaluation. The methanolic extract of $J$. communis was screened by different chemical tests to test the presence of the active chemical constituents such as flavonoids, alkaloids, steroids, terpenoids, glycosides, and phenolic compounds. These tests were performed to get a preliminary idea of the chemical constituents [19-21].

2.5. Determination of $L D_{50} \cdot \mathrm{LD}_{50}$ of the extract was determined following the Organizations for Economic Cooperation and Development (OECD) guidelines. Acute toxicity class method (OECD guideline no. 423) and revised up-anddown method (OECD guideline no. 425) were followed for the testing of chemicals. Animals were observed for 24 hours for toxic symptoms such as behavioral changes, convulsions, locomotion, and mortality. If one animal showed mortality then the same dose was repeated again to confirm the toxic dose. If mortality was not observed, then the same procedure was repeated for further higher doses [22, 23].
2.6. Methodology. Rats were randomly allocated into four groups each containing 6 animals. Animals of Group I were administered with $1 \%$ gum acacia as a vehicle and served as control group. Group II animals were administered with chlorpromazine $3 \mathrm{mg} / \mathrm{kg}$, i.p. (dissolved with $1 \%$ gum acacia in distilled water suspension) daily for a period of 21 days, and served as the negative control group. Group III animals received the combination of carbidopa + levodopa (1:10 ratio) (10 mg/kg, i.p.) and served as standard group. Group IVa and Group IVb animals were administered with methanolic extract of $J$. communis (MEJC) $100 \mathrm{mg} / \mathrm{kg}$ i.p. and $200 \mathrm{mg} / \mathrm{kg}$ i.p., respectively, for a period of 21 days. Chlorpromazine was given 30 minutes prior to standard and test drug. Body weight changes and behavioral assessments were carried out before the start of the treatment. Various parameters like catalepsy (bar test), locomotor activity (actophotometer test), and muscle activity (rotarod test) were measured in all animals [24-26]. After the 21 days, animals were sacrificed and their brains were removed and weighed. A $10 \%$ tissue homogenate was prepared in $0.1 \mathrm{M}$ phosphate buffer ( $\mathrm{pH}$ 8) for TBARS, GSH, nitrites, and total protein.

\subsection{Biochemical Estimation}

2.7.1. Lipid Peroxidation Assay (TBARS). Thiobarbituric acid reactive substances (TBARS) measurement is an index of lipid peroxidation in brain. For the estimation of TBARS, ten percent $(\mathrm{w} / \mathrm{v})$ tissue homogenate was mixed with sodium dodecyl sulfate, acetate buffer ( $\mathrm{pH} 3.5$ ), and aqueous solution of thiobarbituric acid. After heating at $95^{\circ} \mathrm{C}$ for $60 \mathrm{~min}$, the red pigment produced was extracted with $n$-butanolpyridine mixture and estimated by the absorbance at $532 \mathrm{~nm}$. As an external standard, tetramethoxypropane was used, and lipid peroxide level was expressed in terms of nmol malondialdehyde [27].

2.7.2. Estimation of Reduced Glutathione (GSH). For the estimation of reduced glutathione the $1 \mathrm{ml}$ of tissue homogenate was precipitated with $1 \mathrm{ml}$ of $10 \%$ trichloroacetic acid (TCA). To an aliquot of the supernatant $4 \mathrm{ml}$ of phosphate solution and $0.5 \mathrm{ml}$ of $5,5^{\prime}$-dithio-bis-(2-nitrobenzoic acid) (DTNB) reagent were added and absorbance was taken at $412 \mathrm{~nm}$. A standard curve of reduced glutathione was prepared and the concentration of GSH in the supernatant was determined from the standard curve [28].

2.7.3. Estimation of Nitrite. The production of nitric oxide (NO) in the brain may occur due to oxidative stress and it can be determined by estimation of nitrite level. The nitrite level was determined spectrophotometrically with Griess reagent (0.1\% N-1-naphthyl ethylene amine dihydrochloride, $1 \%$ sulphanilamide, and $2.5 \%$ phosphoric acid). Brain homogenate and Griess reagent were mixed equally and this mixture was incubated for $10 \mathrm{~min}$ and the absorbance was measured at $546 \mathrm{~nm}$. The standard curve of sodium nitrite was prepared and the concentration of nitrite in the supernatant was determined from standard curve [29].

2.7.4. Estimation of Protein. For the estimation of protein content of brain, Lowry method was used. Standard curve was determined using bovine serum albumin [30]. 
2.8. Statistical Analysis. Data were analyzed with one-way ANOVAs followed by Tukey's post hoc tests, with significance set to $P<0.001$. All analyses were performed using Sigma Stat (10.0). Results obtained were expressed as mean \pm SEM.

\section{Results}

3.1. Acute Toxicity $\left(L D_{50}\right)$. The Juniperus communis did not produce any mortality up to a dose level of $2000 \mathrm{mg} / \mathrm{kg}$ body weight. Juniperus communis extract showed less solubility so further increment of doses was not possible (according to OECD-423). So, the two dose ranges $100 \mathrm{mg} / \mathrm{kg}$ and $200 \mathrm{mg} / \mathrm{kg}$ were selected.

3.2. Phytochemical Screening of Methanolic Extract of Juniperus communis Leaves. Phytochemical screening of methanolic extract of Juniperus communis leaves showed the presence of alkaloids, flavonoids, glycosides, steroids, and tannins.

\subsection{Effect of MEJC on Chlorpromazine Induced Catalepsy in} Rats. All the animals were evaluated for catalepsy using bar test for 2-4 sec during weekly observation and at last on the 21st day of treatment. The control animals were evaluated for their catalepsy score $(2.1-2.3 \mathrm{sec})$ during the entire observation period.

Animals of Group II were found to retain themselves for a longer duration as compared to the control Group (Group I). The cataleptic behavior (inability to correct abnormal posture) of CPZ treated animals (Group II) was found to increase significantly every weak (increase in mean retention time from $7 \mathrm{sec}$ on the 14th day to $11 \mathrm{sec}$ on the 21st day) and also on the 21st day treatment $(15 \mathrm{sec}, P<0.001)$ when compared to vehicle treated control group (Group I) animals.

The animals treated with levodopa and carbidopa $(10 \mathrm{mg} / \mathrm{kg}$ i.p. $)$ group significantly $(P<0.001)$ prevented the increase in catalepsy when compared to CPZ treated animals (Group II) on the 21st day. The retention time of animals (Group III) on bar was found to reduce significantly (5.29 sec $P<0.001)$ on the 21st day as compared to $2.29 \mathrm{sec}$ (NS), $3.21 \mathrm{sec}(P<0.001)$, and $4.45 \mathrm{sec}(P<0.001)$ on the 0 th, the 7 th, the 14 th, and the 21st days of treatment in comparison to $\mathrm{CPZ}$ treated negative control group (Group II). The animals pretreated with the different doses of MEJC (100 and $200 \mathrm{mg} / \mathrm{kg}$ i.p.) showed a significant decrease in catalepsy score when compared to CPZ treated animals. The MEJC at a dose $(200 \mathrm{mg} / \mathrm{kg}$ i.p. $)$ was found to be significantly on the 21st day (5.2 sec $P<0.001$ ) as compared to 2.3 (NS), $3.37(P<0.01)$, and $5.01(P<0.001)$, on the 0 th, the 7 th, the 14 th, and the 21st days of treatment in comparison to CPZ treated negative control group (Group II) on respective days (Figure 1).

\subsection{Effect of MEJC on Chlorpromazine Induced Muscle Rigid-} ity in Rats. Muscle rigidity of animals was evaluated by using the rotarod apparatus. The mean fall-off time of vehicle treated control group (Group I) animals from the rotarod was found to be 116.2-116.5 seconds during weekly observation of the treatment.

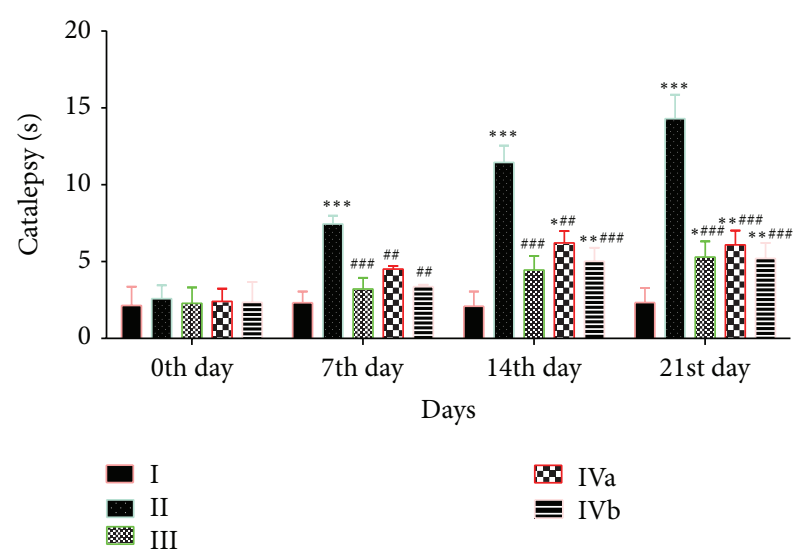

FIgURE 1: Effect of MEJC on chlorpromazine induced catalepsy in rats. ${ }^{*} P<0.05,{ }^{* *} P<0.01$, and ${ }^{* * *} P<0.001$ as compared to vehicle treated control group (Group I). ${ }^{\#} P<0.05$, ${ }^{\# \#} P<0.01$, and ${ }^{\# \# \#} P<$ 0.001 as compared to chlorpromazine treated negative control group (Group II).

CPZ treated groups (Group II) showed a nonsignificant difference in muscle rigidity on the 0th day $(103.9 \pm 2.730)$ which then significantly reduced every week. The rotarod readings (muscle rigidity) decreased to $83.5 \pm 3.940$ on the 7 th day, to $60.29 \pm 1.720$ on the 14 th day, and finally to $38.5 \pm$ 1.730 on the 21 st day. Then there was a significant decrease $(P<0.001)$ in the muscle activity of CPZ treated group when compared to control group.

The animals treated with standard drug (10 mg/kg i.p.) also showed a nonsignificant increase in muscle activity on the 0th day (111.8 \pm 3.990$)$, which then significantly increased $(P<0.001)$ on the 7 th day $(109.74 \pm 4.730)$, the 14 th day $(99.5 \pm 2.050)$, and the 21 st day $(97.5 \pm 2.110)$ when compared to $\mathrm{CPZ}$ treated (Group II) animals on the same day, whereas pretreatment with MEJC (Group IV) at a dose of $100 \mathrm{mg} / \mathrm{kg}$ i.p. showed a rotarod reading $106.3 \pm 1.930$ on the 0 th day and a significant increase $(P<0.05)$ in muscle activity on the 7 th day of treatment as compared to Group II. A significant increased $(P<0.01)$ activity was observed on the 14th day $(71.5 \pm 1.890)$ and on the 21st day $(65.2 \pm 3.760)$.

The dose of MEJC (200 mg/kg i.p.) also showed a significant activity $(P<0.01)$ on the 7 th day $(104.5 \pm 4.150)$ as compared to Group II. A significant activity $(P<0.001)$ was observed on the 14 th day $(89.5 \pm 2.340)$ and on the 21 st day $(75.73 \pm 5.320)$ as compared to negative control group (Group II) (Figure 2).

3.5. Effect of MEJC on Chlorpromazine Induced Hypolocomotion in Rats. Locomotor activity of animals was evaluated using actophotometer. Locomotor activity of vehicle treated control group (Group I) was found to be $71-73$ counts $/ 5 \mathrm{~min}$ for all the four weeks of treatment.

CPZ treatment of animals of Group II showed a nonsignificant difference in locomotion on the 0th day (71.93 \pm 1.930) which then significantly reduced every week. The actophotometer readings decreased to $57.5 \pm 1.980$ on the 7 th day, to $42.5 \pm 2.870(P<0.001)$ on the 14 th day, and finally 


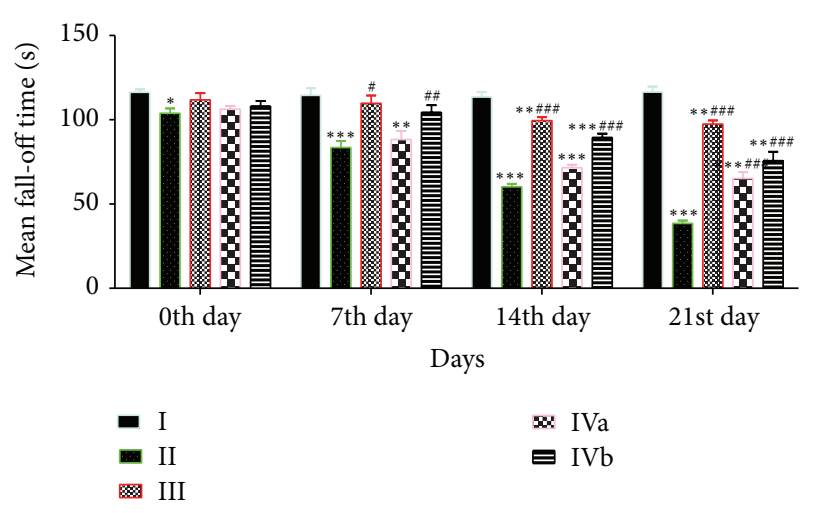

FIGURE 2: Effect of MEJC on chlorpromazine induced muscle rigidity in rats. ${ }^{*} P<0.05,{ }^{* *} P<0.01$, and ${ }^{* * *} P<0.001$ as compared to vehicle treated control group (Group I). ${ }^{\#} P<0.05$, ${ }^{\# \#} P<0.01$, and ${ }^{\# \# \#} P<0.001$ as compared to chlorpromazine treated negative control group (Group II).

to $33.5 \pm 1.230$ on the 21 st day. Then there was a significant decrease $(P<0.001)$ in the locomotor activity of $\mathrm{CPZ}$ treated negative control animals (Group II) when compared to control group (Group I).

Animals treated with standard drug (10 mg/kg i.p.) showed a nonsignificant variance in locomotor activity on the 0th day $(69.98 \pm 2.730)$ which then significantly increased in locomotor activity on the 7 th day $(71.43 \pm 2.820)$, on the 14 th day $(63.5 \pm 1.770, P<0.001)$, and on the 21st day $(62.21 \pm$ $1.230, P<0.001)$. Thus there was a significant increase $(P<$ $0.001)$ in the locomotor activity of Group III when compared to Group I, whereas pretreatment with MEJC (Group IV) showed significant $(P<0.001)$ changes in locomotor activity. Animals treated with the 1 st dose $(100 \mathrm{mg} / \mathrm{kg}$ i.p.) showed a nonsignificant difference in the 0th day $(71.32 \pm 2.070)$ and then a gradual increase in locomotor activity on the 7 th day $(65.5 \pm 1.120, P<0.05)$, on the 14 th day $(52.5 \pm 2.430, P<$ $0.05)$, and finally on the 21 st day $(57.23 \pm 1.830, P<0.001)$.

Animals treated with second dose $(200 \mathrm{mg} / \mathrm{kg}$ i.p. $)$ also showed a highly significant activity on the 21st day (60.02 \pm 2.830, $P<0.001)$ when compared to negative control group (Group II). The present study showed that the MEJC has significant protection in CPZ induced hypolocomotion (Figure 3).

3.6. Effect of MEJC on the TBARS Level in Rat Brain. The TBARS level in control group (Group I) animals was found to be $1.736 \pm 0.8320 \mathrm{nM} / \mathrm{mg}$ proteins and that of animals treated with levodopa and carbidopa (Group II) was found to be $1.876 \mathrm{nM} / \mathrm{mg}$ proteins. Then there was a significant difference $(P<0.01)$ found between these two groups.

The animals treated with CPZ (Group II) showed a significant increase in TBARS level in brain ((4.675 \pm $0.035) \mathrm{nM} / \mathrm{mg}$ protein, $P<0.001)$ of $\mathrm{CPZ}$ treated animals as compared to control group (Group I). Pretreatment with MEJC (Group IVa and Group IVb) showed a significant reduction in level of TBARS in brain (IVa-2.377 \pm 0.1240 and IVb-1.93 $\pm 0.9432, P<0.01)$ when compared to CPZ treated animals (Group II), respectively (Table 1).

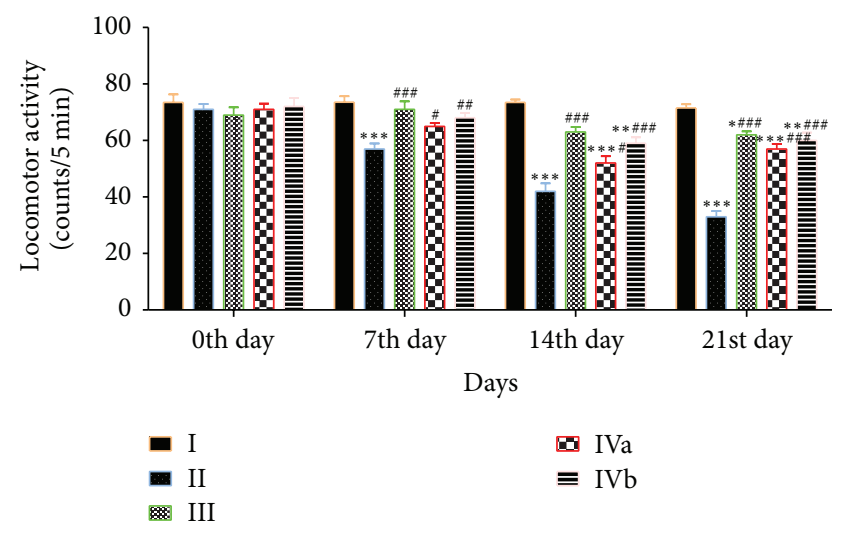

FIGURE 3: Effect of MEJC on chlorpromazine induced hypolocomotion in rats. ${ }^{*} P<0.05,{ }^{* *} P<0.01$, and ${ }^{* * *} P<0.001$ as compared to vehicle treated control group (Group I). ${ }^{\#} P<0.05,{ }^{\# \#} P<0.01$,

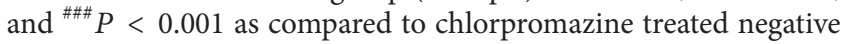
control group (Group II).

3.7. Effect of MEJC on the GSH Level in Rat Brain. GSH level in control group (Group I) animals was found to be $5.826 \pm 0.6670 \mu \mathrm{M} / \mathrm{mg}$ protein. The animals treated with $\mathrm{CPZ}$ (Group II) showed a significant decrease in GSH levels in brain $(1.920 \pm 0.0435, P<0.01)$ as compared to control group (Group I) animals.

The GSH level in Group III treated with standard drug was increased up to $(4.654 \pm 0.720)$ as compared to CPZ treated animals (Group II). The pretreatment with MEJC showed a significant increase in level of GSH in brain (IVa$4.092 \pm 0.5350, P<0.005$ and IVb 5.2874 $\pm 0.572, P<$ 0.001) when compared to CPZ treated animals (Group II), respectively (Table 1).

3.8. Effect of MEJC on the Nitrite Level in Rat Brain. Nitrite level in control group (Group I) animals was found to be $2.941 \pm 0.4250 \mathrm{nM} / \mathrm{mg}$ proteins. Chronic CPZ treatment to rats for 21 days induced lipid peroxidation indicated by a significant rise in nitrite level in brain $(6.143 \pm 0.5210) P<$ 0.001 as compared with control group animals (Group I).

The animals treated with standard drug (Group III) had significantly reduced the nitrite level to $(3.375 \pm 0.6260) P<$ 0.001 as compared to negative control group (Group II). The animals pretreated with two doses of MEJC also showed a significant reduction in nitrite level (Group IVa-3.442 \pm 0.7370, $P<0.05$., Group IVb-3.102 $\pm 0.4600, P<0.001)$, respectively, as compared to negative control animals (Group II) (Table 1).

3.9. Effect of MEJC on the Total Protein Level in Rat Brain. Protein level in control group (Group I) was found to be $11.143 \pm 0.5160$ and level was significantly decreased $(P<$ 0.001 ) in chronic treatment with CPZ group (Group II) $(6.143 \pm 0.5210)$ as compared to control or vehicle treated group (Group I) animals. The animals treated with levodopa+carbidopa (Group III) showed a significant increase in protein level $(9.953 \pm 0.7120 \mathrm{mg} / \mathrm{mL}, P<0.001)$ in brain as compared with negative group (Group II). 
TABLE 1: Effect of MEJCon the different parameters in rat brain.

\begin{tabular}{lcccc}
\hline Groups & $\begin{array}{c}\text { GSH level } \\
(\mathrm{nM} / \mathrm{mg} \text { protein) } \\
\text { mean } \pm \text { SEM }\end{array}$ & $\begin{array}{c}\text { Nitrite level } \\
(\mathrm{nM} / \mathrm{mg} \text { of protein) } \\
\text { mean } \pm \text { SEM }\end{array}$ & $\begin{array}{c}\text { Total protein level } \\
(\mathrm{mg} / \mathrm{mL}) \\
\text { mean } \pm \text { SEM }\end{array}$ & $\begin{array}{c}\text { TBARS level } \\
(\mathrm{nM} / \mathrm{mg} \text { protein) } \\
\text { mean } \pm \text { SEM }\end{array}$ \\
\hline I (control group) & $5.826 \pm 0.6670$ & $2.941 \pm 0.4250$ & $11.143 \pm 0.5160$ & $1.736 \pm 0.08320$ \\
II (negative control) & $1.920 \pm 0.0435^{\mathrm{a}}$ & $6.776 \pm 0.5260^{\mathrm{a}}$ & $6.143 \pm 0.5210^{\mathrm{a}}$ & $4.675 \pm 0.0350^{\mathrm{a}}$ \\
III (standard group) & $4.654 \pm 0.0720^{\mathrm{NS}, \mathrm{y}}$ & $3.375 \pm 0.6260^{\mathrm{NS}, \mathrm{x}}$ & $9.953 \pm 0.7120^{\mathrm{NS}, \mathrm{x}}$ & $1.876 \pm 0.0270^{\mathrm{y}}$ \\
IVa (Test 1) & $4.092 \pm 0.5350^{\mathrm{NS}, \mathrm{z}}$ & $3.442 \pm 0.7370^{\mathrm{NS}, \mathrm{y}}$ & $7.571 \pm 0.03730^{\mathrm{a}, \mathrm{z}}$ & $2.377 \pm 0.1240^{\mathrm{NS}, \mathrm{y}}$ \\
IVb (Test 2) & $5.2874 \pm 0.5720^{\mathrm{NS}, \mathrm{x}}$ & $3.102 \pm 0.4600^{\mathrm{NS}, \mathrm{x}}$ & $8.98 \pm 0.4230^{\mathrm{c}, \mathrm{y}}$ & $1.93 \pm 0.9432^{\mathrm{NS}, \mathrm{y}}$ \\
\hline
\end{tabular}

$\mathrm{a}=* * *(P<0.001), \mathrm{b}=* *(P<0.01)$, and $\mathrm{c}=*(P<0.05)$ when compared with control group.

$\mathrm{x}=\# \#(P<0.001), \mathrm{y}=\#(P<0.01)$, and $\mathrm{z}=\#(P<0.05)$ when compared with negative control group.

The animals pretreated with MEJC $(100 \mathrm{mg} / \mathrm{kg}$ and $200 \mathrm{mg} / \mathrm{kg}$ i.p.) also showed a significant increase in protein level (IVa-7.571 \pm 0.03730, $P<0.05 . ;$ IVb-8.98 \pm 0.4230 , $P<0.01$ ) in brain as compared to negative group (Group II) animals (Table 1$)$.

\section{Discussion}

Parkinson is a brain disorder which is clinically characterized by bradykinesia, resting tremor, and postural instability. In Parkinson disease the depletion of dopamine (DA) may occur. Parkinson disease occurs due to the degeneration of dopaminergic neurons in the substantia nigra pars compacta [31]. Various plants have been used for the treatment of neurodegenerative disease like Parkinson disease. Various animal models have been developed for the evaluation of Parkinson's disease and are generated through the administration of toxins. The purpose of the present study was to evaluate the antiparkinson activity of $J$. communis leaves in rats treated with chlorpromazine.

Chlorpromazine is one of the antipsychotic drugs listed as essential drugs by WHO in 2003 [32-34] to treat both acute psychosis and chronic psychosis. It has been associated with side effects such as antidopaminergic extra pyramidal syndromes [35], dry mouth, blurred vision, and urinary retention (anticholinergic) [36], narcoleptic dysphoria, blood pressure disturbances, temperature and muscle control, diminished libido, erectile impotence, and ejaculation inhibition in male patients [37]. Chronic treatments with $\mathrm{CPZ}$ increase the dopamine receptor binding site in neostriatum and in mesolimbic region, which could account for dopamine hypersensitivity that induced tardive dyskinesia [38]. Chlorpromazine induced Parkinsonism by interfering with the storage of catecholamines in intracellular granules which may cause monoamine depletion in nerve terminals and in the induction of hypolocomotion and muscular rigidity [3942]; thus, CPZ was produced by the Parkinson disease-like symptoms [43] followed by chronic treatments of rats for 21 days. It results in an increase level of oxidative stress that may cause the reduction in antioxidant enzymes which were also seen with the atypical agent's ziprasidone, risperidone, and olanzapine. Except olanzapine both typical and atypical agents increase lipid peroxidation after chronic dosing [36]. There was a significant increase in catalepsy, a decrease in movements, and a decrease in body weight following chlorpromazine administration to rats. The present data suggested that chlorpromazine developed Parkinson's diseaselike behavioral symptoms in rats. The oxidative stress was measured through determination of levels of TBARS, reduced glutathione, and nitrite level in brain tissue. Lipid peroxidation is a sensitive marker of oxidative stress. Lipid peroxidation occurs due to attack by radicals on double bond of unsaturated fatty acid and arachidonic acid which generate lipid peroxyl radicals. These radicals have further attacks on other unsaturated fatty acids [44]. Increased levels of the lipid peroxidation product have been found in the substantia nigra of PD patients [40]. In the present study the same result was observed in the brain homogenates of chlorpromazine treated negative control animals. Brain protects against oxidative stress by SOD, catalase, and glutathione peroxidase and thus these antioxidant enzymes protect brain from neurodegeneration. Glutathione peroxidase protects brain from neurodegeneration by scavenging $\mathrm{H}_{2} \mathrm{O}_{2}$ generated by cellular metabolism and balance formation and decomposition of $\mathrm{H}_{2} \mathrm{O}_{2}$ in normal condition. It is obvious that reduced glutathione is the limiting factor in the removal of $\mathrm{H}_{2} \mathrm{O}_{2}$. Neuronal cell loss may cause the depletion of reduced glutathione in the substantia nigra in Parkinson disease [45]. Nitric oxide production can be determined by nitrite determinations in biological material. We detected nitrite in the rat brain homogenates by the Griess method [46]. Nitric oxide has been involved in the cytotoxicities by activation of macrophages or excess stimulation of neurons by glutamate. In further study on glutamate stimulation causes neurotoxicity in primary cultures of rat fetal cortical, striatal, and hippocampal neurons [29]. CPZ group showed a significant increase in the level of TBARS and gradual decrease in GSH levels in brain as compared control group. All observations showed that chlorpromazine increases the oxidative stress in the brain of animals. Two doses of methanolic extract of J. communis (100 and $200 \mathrm{mg} / \mathrm{kg}$, i.p.) were used in the chlorpromazine model in rats; both doses were found to be significant in reducing the catalepsy, increasing the locomotor activity (actophotometer), and increasing the muscle activity (rotarod test) in a chlorpromazine model of Parkinson in rats which indicates J. communis has potential effects against Parkinson's disease-like symptoms produced in various experimental models. The antioxidative properties of $J$. communis reduced the duration of the catalepsy that decreased the elevated levels of lipid peroxidation in the chlorpromazine treated animals. 


\section{Conclusion}

Juniperus communis earlier proved to be an antioxidant and showed a promising effect in animals with Parkinson's disease. The above findings suggest that Juniperus communis may offer a safer therapeutic approach to the treatment of Parkinson's disease.

\section{Conflict of Interests}

The authors declare that there is no conflict of interests regarding the publication of this paper.

\section{References}

[1] K. L. Leenders and W. H. Oertel, "Parkinson's disease: clinical signs and symptoms, neural mechanisms, positron emission tomography, and therapeutic interventions," Neural Plasticity, vol. 8, no. 1-2, pp. 99-110, 2001.

[2] H. Braak, U. Rüb, W. P. Gai, and K. Del Tredici, "Idiopathic Parkinson's disease: possible routes by which vulnerable neuronal types may be subject to neuroinvasion by an unknown pathogen," Journal of Neural Transmission, vol. 110, no. 5, pp. 517-536, 2003.

[3] A. M. Karch, Focus on Nursing Pharmacology, Lippincott Williams \& Wilkins, Philadelphia, Pa, USA, 5th edition, 2009.

[4] S. Nikam, P. Nikam, S. K. Ahaley, and A. V. Sontakke, "Oxidative stress in Parkinson's disease," Indian Journal of Clinical Biochemistry, vol. 24, no. 1, pp. 98-101, 2009.

[5] S. J. Clifton, L. K. Ward, and D. S. Ranner, "The status of juniper Juniperus communis L. In North-East England," Biological Conservation, vol. 79, no. 1, pp. 67-77, 1997.

[6] C. Kailash, B. G. Chaudhari, B. P. Dhar et al., Database on Medicinal Plants Used in Ayurveda, vol. 8, Central Council for Research in Ayurveda \& Siddha, 2007.

[7] S. Bais, N. S. Gill, N. Rana, and S. Shandil, "A phytopharmacological review on a medicinal plant: Juniperus communis," International Scholarly Research Notices, vol. 2014, Article ID 634723, 6 pages, 2014

[8] M. Hoferl, I. Stoilova, E. Schmidt et al., "Chemical composition and antioxidant properties of juniper berry (Juniperus communis L.) essential oil. Action of the essential oil on the antioxidant protection of Saccharomyces cerevisiae model organism," Antioxidants, vol. 3, no. 1, pp. 81-98, 2014.

[9] C. P. Khare, Indian Medicinal Plants, Springer, New York, NY, USA, 2007.

[10] S. Banerjee, A. Mukherjee, and T. K. Chatterjee, "Evaluation of analgesic activities of methanolic extract of medicinal plant Juniperus communis linn," International Journal of Pharmacy and Pharmaceutical Sciences, vol. 4, no. 5, pp. 547-550, 2012.

[11] S. C. Sati and S. Joshi, "Antibacterial potential of leaf extracts of Juniperus communis L. from Kumaun Himalaya," African Journal of Microbiology Research, vol. 4, no. 12, pp. 1291-1294, 2010.

[12] G. G. P. Manvi, "Screening and evaluation of pharmacognostic, phytochemical and hepatoprotective activity of linn stems," International Journal of Pharma and Bio Sciences, vol. 1, no. 3, 2010.

[13] M. Akdogan, A. Koyu, M. Ciris, and K. Yildiz, "Anti-hypercholesterolemic activity of Oil in rats: a biochemical and histopathological investigation," Biomedical Research, vol. 23, no. 3, pp. 321-328, 2012.

[14] H. Tunón, C. Olavsdotter, and L. Bohlin, "Evaluation of antiinflammatory activity of some Swedish medicinal plants. Inhibition of prostaglandin biosynthesis and PAF-induced exocytosis," Journal of Ethnopharmacology, vol. 48, no. 2, pp. 61-76, 1995.

[15] S. Banerjee, H. Singh, and T. K. Chatterjee, "Evaluation of anti-diabetic and anti-hyperlipidemic potential of methanolic extract of Juniperus Communis (L.) in StreptozotocinNicotinamide induced diabetic rats," International Journal of Pharma and Bio Sciences, vol. 4, no. 3, pp. P10-P17, 2013.

[16] S. Bais, N. S. Gill, and N. Rana, "Effect of Juniperus communis extract on reserpine induced catalepsy," Inventi Rapid: Ethnopharmacology, vol. 2014, no. 4, pp. 117-120, 2014.

[17] S. Pepeljnjak, I. Kosalec, Z. Kalodera, and N. Blažević, "Antimicrobial activity of juniper berry essential oil (Juniperus communis L., Cupressaceae)," Acta Pharmaceutica, vol. 55, no. 4, pp. 417-422, 2005.

[18] L. Chen, Y. Ding, B. Cagniard et al., "Unregulated cytosolic dopamine causes neurodegeneration associated with oxidative stress in mice," Journal of Neuroscience, vol. 28, no. 2, pp. 425433, 2008.

[19] C. K. Kokate, Practical Pharmacognosy, Vallabh Prakashan, 2005.

[20] K. R. Khandelwal, Practical Pharmacognosy Techniques and Experiments, 11th edition, 2004.

[21] G. E. Trease and W. C. Evans, Pharmacognosy, Bailliere Tindall, London, UK, 11th edition, 1989.

[22] OECD/OCDE 423 Annex 2, "Procedure to be followed for each of the starting doses," in OECD Guideline For Testing of Chemicals, Acute Oral Toxicity-Acute Toxic Class Method, pp. 1/14-14/14, 2001.

[23] D. J. Ecobichnon, The Basis of Toxicity Testing, CRC Press, New York, NY, USA, 2nd edition, 1997.

[24] B. Costall and R. J. Naylor, "On catalepsy and catatonia and the predictability of the catalepsy test for neuroleptic activity," Psychopharmacologia, vol. 34, no. 3, pp. 233-241, 1974.

[25] M. Bishnoi, K. Chopra, and S. K. Kulkarni, "Involvement of adenosinergic receptor system in an animal model of tardive dyskinesia and associated behavioural, biochemical and neurochemical changes," European Journal of Pharmacology, vol. 552, no. 1-3, pp. 55-66, 2006.

[26] S. K. Kulkarni, Handbook of Experimental Pharmacology, Vallabh Prakashan, New Delhi, India, 2008.

[27] H. Ohkawa, N. Ohishi, and K. Yagi, "Assay for lipid peroxides in animal tissues by thiobarbituric acid reaction," Analytical Biochemistry, vol. 95, no. 2, pp. 351-358, 1979.

[28] M. S. Moron, J. W. Depierre, and B. Mannervik, "Levels of glutathione, glutathione reductase and glutathione S-transferase activities in rat lung and liver," Biochimica et Biophysica Acta, vol. 582, no. 1, pp. 67-78, 1979.

[29] R. Lidija, S. Vesna, J. Branka, and T. L. Dajana, "Effect of glutamate antagonists on nitric oxide production in rat brain following intrahippocampal injection," Archives of Biological Sciences, vol. 59, no. 1, pp. 29-36, 2007.

[30] O. H. Lowry, N. J. Rosenbrough, A. L. Farr, and R. J. Randall, "Protein measurement with the Folin phenol reagent," The Journal of Biological Chemistry, vol. 193, no. 1, pp. 265-275, 1951.

[31] C. W. Olanow and W. G. Tatton, "Etiology and pathogenesis of Parkinson's disease," Annual Review of Neuroscience, vol. 22, pp. 123-144, 1999. 
[32] World Health Organization (WHO), Essential Medicines, WHO Model List, 13th edition, 2007.

[33] World Health Organization, Management of Substance Abuses the Bare Facts, WHO, 2010.

[34] A. Pillai, A. V. Terry Jr., and S. P. Mahadik, "Differential effects of long-term treatment with typical and atypical antipsychotics on NGF and BDNF levels in rat striatum and hippocampus," Schizophrenia Research, vol. 82, no. 1, pp. 95-106, 2006.

[35] J. M. Pierre, "Extrapyramidal symptoms with atypical antipsychotics: incidence, prevention and management," Drug Safety, vol. 28, no. 3, pp. 191-208, 2005.

[36] H. R. Greenberg, "Inhibition of ejaculation by chlorpromazine.," Journal of Nervous and Mental Disease, vol. 152, no. 5, pp. 364-366, 1971.

[37] R. M. Allen, "Dopamine hypersensitivity and tardive dyskinesia.," The American Journal of Psychiatry, vol. 134, no. 10, pp. 1154-1155, 1977.

[38] S. K. Kulkarni, Handbook of Experimental Pharmacology, Vallabh Prakashan, New York, NY, USA, 3rd edition, 1999.

[39] D. T. Dexter, A. E. Holley, W. D. Flitter et al., "Increased levels of lipid hydroperoxides in the Parkinsonian substantia nigra: an HPLC and ESR study," Movement Disorders, vol. 9, no. 1, pp. 9297, 1994.

[40] V. Parikh, M. M. Khan, and S. P. Mahadik, "Differential effects of antipsychotics on expression of antioxidant enzymes and membrane lipid peroxidation in rat brain," Journal of Psychiatric Research, vol. 37, no. 1, pp. 43-51, 2003.

[41] K. D. Tripathi, Essentials of Medical Pharmacology, Jaypee Brothers Medical Publishers, 6th edition, 2008.

[42] K. S. Sandhu and A. C. Rana, "Evaluation of anti parkinson's activity of Nigella sativa (kalonji) seeds in chlorpromazine induced experimental animal model," International Journal of Pharmacy and Pharmaceutical Sciences, vol. 5, p. 3, 2013.

[43] K. J. Barnham, C. L. Masters, and A. I. Bush, "Neurodegenerative diseases and oxidative stress," Nature Reviews Drug Discovery, vol. 3, no. 3, pp. 205-214, 2004.

[44] G. Nikolova, "Oxidative stress and Parkinson disease," Trakia Journal of Sciences, vol. 10, no. 1, pp. 171-172, 2012.

[45] I. Guevara, J. Iwanejko, A. Dembińska-Kieć et al., "Determination of nitrite/nitrate in human biological material by the simple Griess reaction," Clinica Chimica Acta, vol. 274, no. 2, pp. 177188, 1998.

[46] V. L. Dawson, T. M. Dawson, D. A. Bartley, G. R. Uhl, and S. H. Snyder, "Mechanisms of nitric oxide-mediated neurotoxicity in primary brain cultures," The Journal of Neuroscience, vol. 13, no. 6, pp. 2651-2661, 1993. 

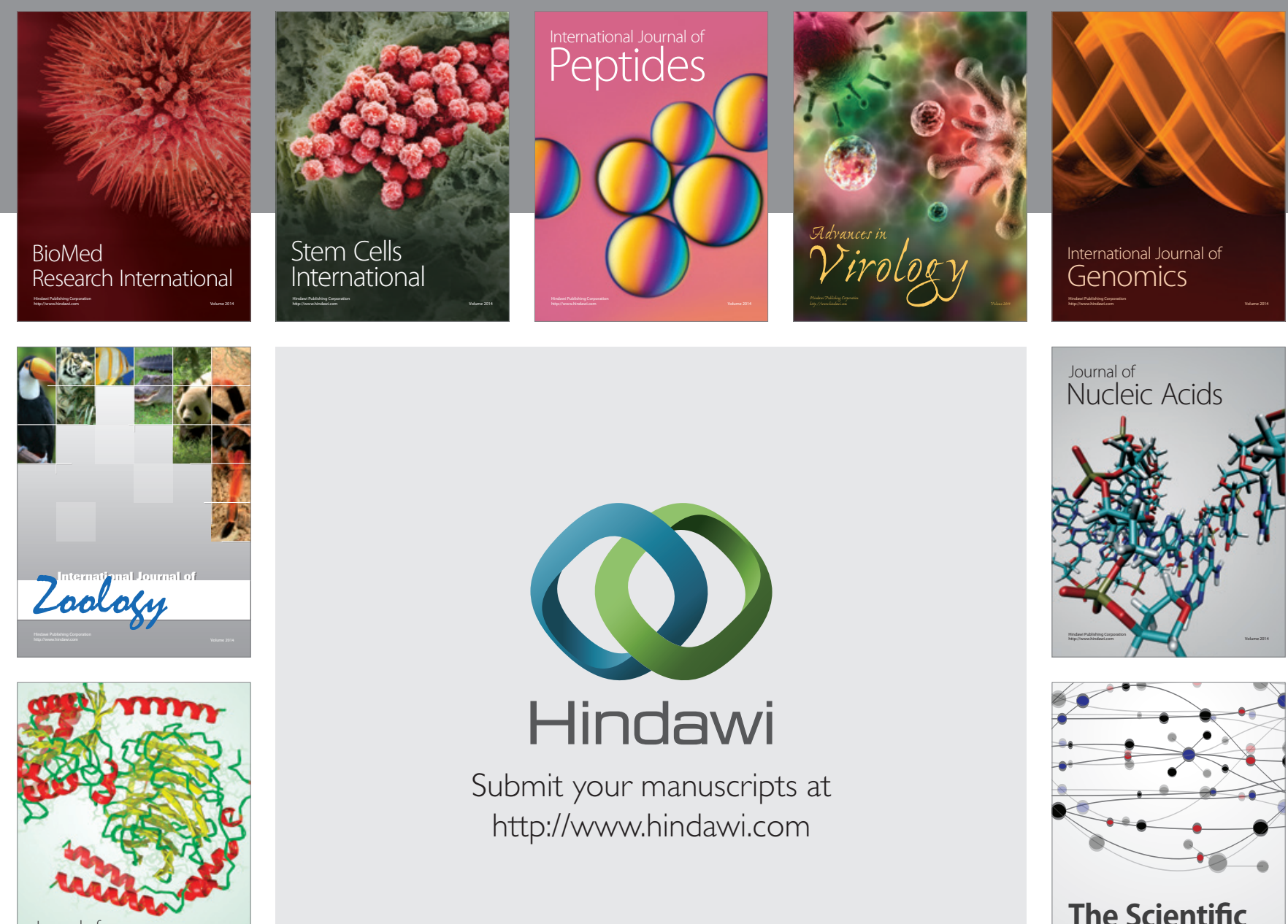

Submit your manuscripts at

http://www.hindawi.com

Journal of
Signal Transduction
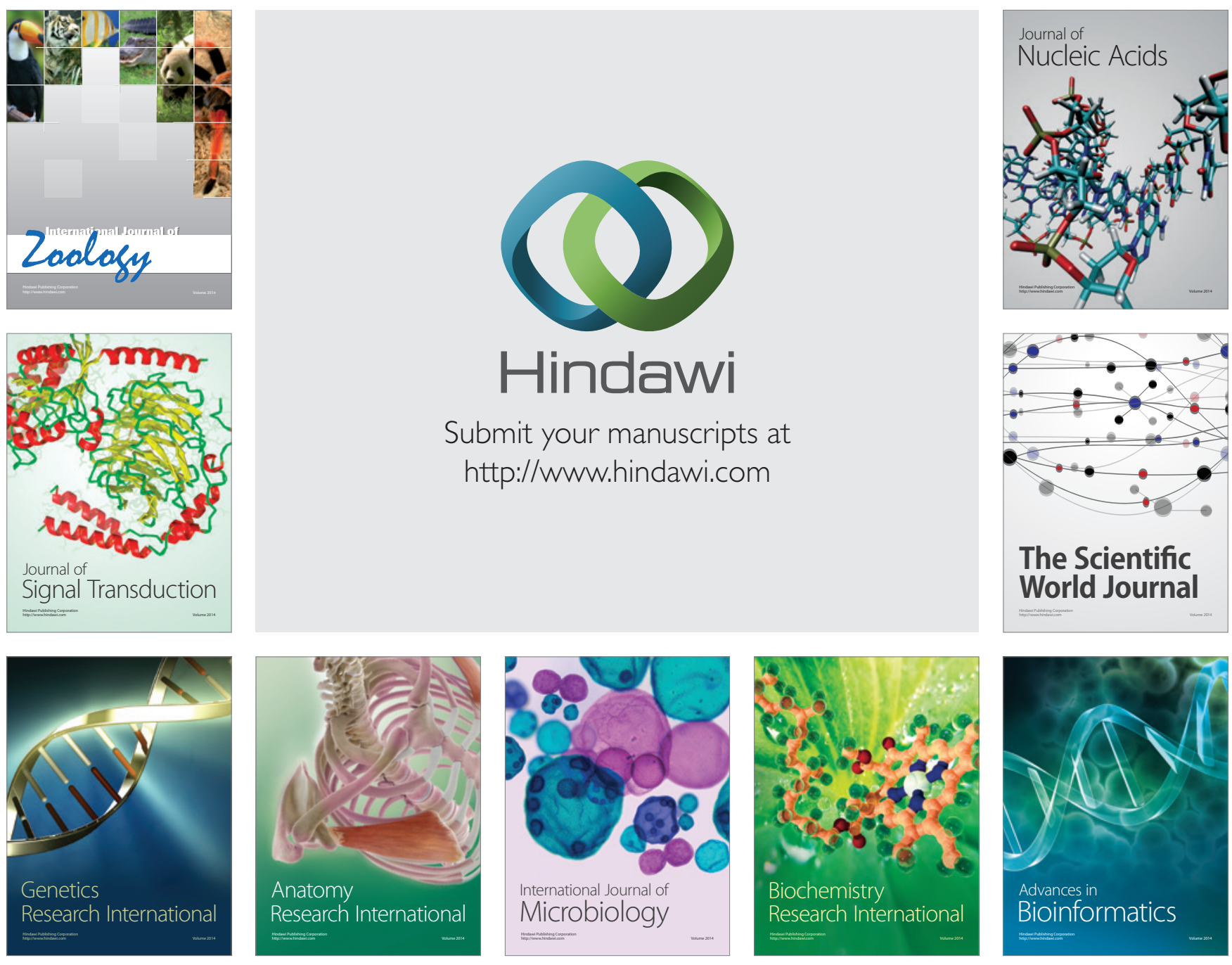

The Scientific World Journal
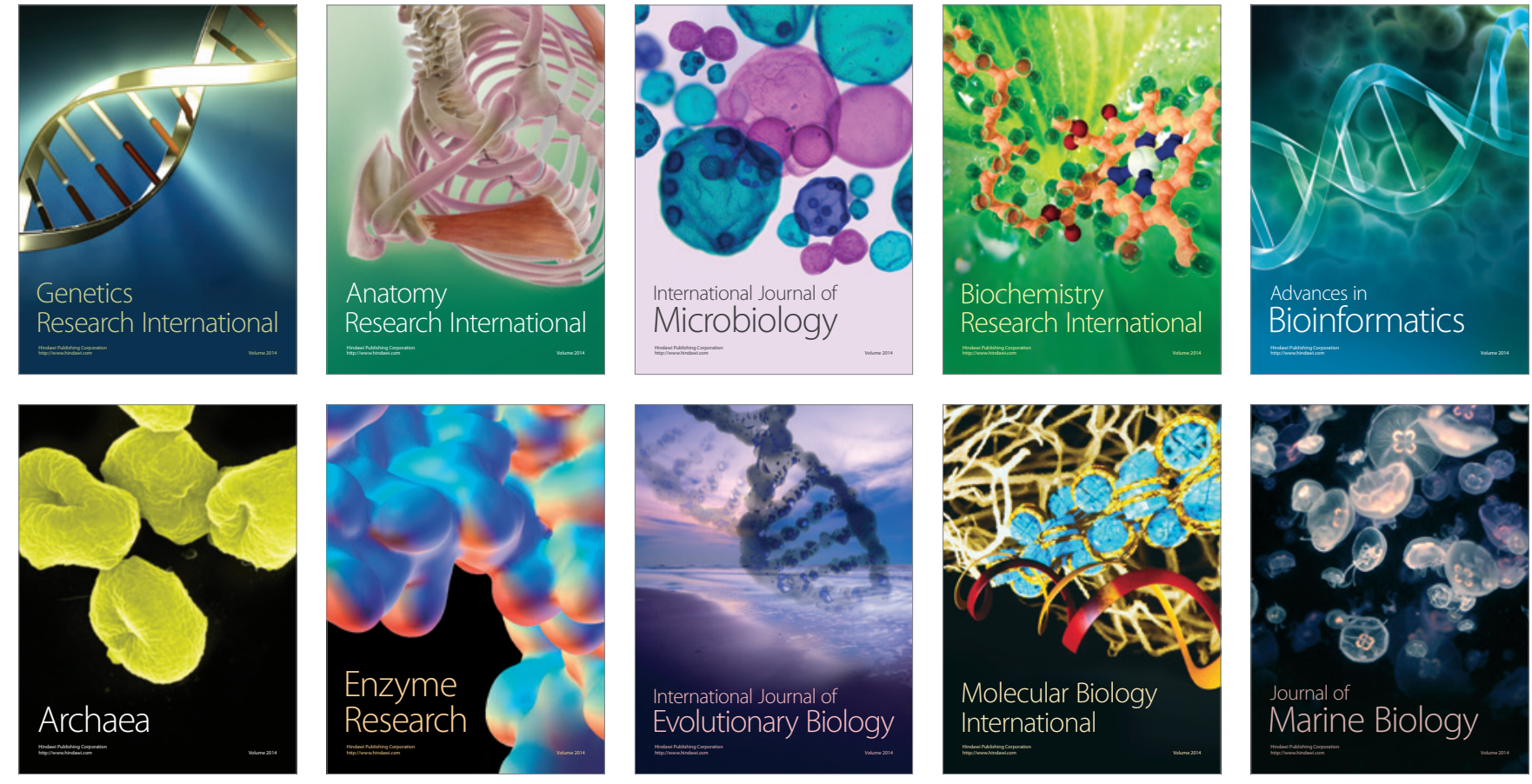